\title{
The Construction of World-class Universities and World-class Disciplines: Reasons, Targets and Measures
}

\author{
Lv Xiao-hong ${ }^{1, *}$ \\ ${ }^{1}$ Institute of Education Sciences, Wuhan University, Wuhan, Hubei 430072
}

\begin{abstract}
Based on "Project 985" and "project 211", The Overall Plan to Promote the Construction of World-class Universities and World-class Disciplines is designed for China's transition from a big country in higher education to a powerful country in higher education, it aims at constructing a group of universities and disciplines with world advanced levels and Chinese characteristics. The building of these two "world-class" relies on five construction tasks to improve the "hard power" and five reform tasks to enhance the "soft power".
\end{abstract}

Keywords: world-class universities; world-class disciplines; a powerful country; discipline groups.

\section{Introduction}

November 5, 2015, the State Council issued the "co-ordination to promote world-class universities with leading disciplines overall program" (referred to as "Double world-class" building). It is intended to enhance our core competitiveness and international influence higher education, for building an innovative country and a powerful human capital to provide a solid pool of talent. What " double world-class " is difference between the pre-construction and implementation of the "211" project, any difference between the "985" project? " double world-class " construction goal is what? How to achieve the goal? This study will recite.

1 Why raise the "double world-class" building?

Since 1999, enrollment, expanding the scale of China's higher education. 1995 colleges and universities only 290.64 million in the number of college students, colleges and universities to expand in 1999 when 408.59 million, as of 2014, has increased to 2547.70 million, an increase of nearly 9 times. 1995, colleges and universities have 1054, 1999, college enrollment increased slightly at the beginning of 1071, but as of 2014, colleges and universities increased to 2529, 1995 is 2.36 times. In this sense, China's colleges and universities have turned to public education from elite education. Universities began to become crowded, schools are students from 1995 to 2014, 0.28 million to 1.01 million.

Expanding in size, while also focusing on the national security of the quality of higher education, has strengthened enjoys a high academic reputation, with first-class platform and discipline of teachers colleges and universities focus on construction, such as the familiar "985" project and "211" engineering. As was responsible for "211" government-led project said: "Development of the University there is a cumulative distribution function, a small number of high-level university has a high educational quality, affordable primary task of a country's development of higher education therefore, be strengthened. Focus on building of higher education, the establishment of a new system with Chinese characteristics of modern higher education, constantly optimize the structure of higher education in the new century higher education reform and development is an important task ${ }^{[1]}$." It is undeniable that the key construction indeed achieved significant results. The "211" project as an example, it makes discipline construction has made significant results, significantly enhance the overall strength of the school, also built with the world, effective and efficient public service system of higher education, while promoting reform and innovation, promoting comprehensive education coordinated development ${ }^{[2]}$. But with the "expansion" and "focus on building" a flood of social issues more worthy of ponder on this, States "double class" construction program, designed to eliminate the "985", "211" project brought questions and further accelerate China's pace of building the world of higher education powers ${ }^{[3]}$. As Suzhou University President Zhu Xiulin in the People's Daily published comments: Compared with the 211, 985, "two-class" had a more modest building open, to encourage the development of the characteristics of category forward. Adhere to the discipline-based, clearly differentiated university development orientation, both moderate development of a 
comprehensive university, but also support and encourage the development of small and fine, professional characteristics of the school. Meanwhile, the "two-class" building outstanding performance-oriented, establish a dynamic adjustment mechanism, so that the "more comprehensive universities involved in improving the country's overall competitiveness, will fully stimulate the vitality of the national university school especially at the local university ${ }^{[4]}$."

\section{The Basic Objectives of "Double world-class" Construction}

What doubleworld-class building goals? In accordance with the "double world-class" building program: short-term goal is that by 2020, a number of universities and a number of disciplines into the world-class ranks of several disciplines into the forefront of world-class discipline; medium-term goal is that by 2030, more universities and disciplines enter the ranks of world-class, a number of universities in the forefront of world-class universities, a number of disciplines into the forefront of world-class disciplines, the overall strength significantly improve higher education; long-term goal is the middle of this century, and first-class university discipline and strength to enter the number of the world basically completed in Higher Education.

\subsection{The Relationship of World-class University and World-class Disciplines}

What is the relationship of world-class university and world-class disciplines is? " Double world-class " building program provided a clear explanation: "China has a number of leading international forefront of high-level university disciplines, to build a world-class discipline in many fields, forming a group of mutual support, joint development of class disciplines, to enhance comprehensive strength and international competitiveness, or to enter the ranks forefront of world-class universities. Some have a university at the forefront of the domestic, living in a dominant position in the international similar institutions in the high level of discipline, should focus on main disciplines, strengthen school characteristics, the construction of a number of class disciplines expand the international influence, driving school similar colleges and universities into the forefront of the world. University has a high level of discipline, to highlight the advantages of discipline, enhance the level of discipline into the forefront of world-class ranks or subject areas. "

Comes down, we believe that the "double first-class" construction is to form a first-class disciplines and interdisciplinary community. Discipline is a multi-disciplinary community "Community", promoted by the various disciplines symbiotic, organic integration. The university is to have more than one class of subject communities "community" community in the various disciplines complementary, joint development.

Class discipline is the foundation, which is based on local institutions "cornerstone." College discipline construction work carried out basically revolves around its own advantages discipline to be expanded. But only a first-class discipline is still very thin, often first-class discipline should reinforce the strength of the subject, we should also continue to expand the extension, combined with technological development trends and national social demand so subject to plump up. In traditional Northeast Normal Normal Schools, for example, it is based on the traditional disciplines of education set up autonomous doctoral mathematics education, rural education, teacher education three two disciplines. These three disciplines and further consolidate the foundation disciplines of education, and formed a unique institutions subject characteristics.

Discipline is a world-class community is the core, it is a world-class university colleges compete for the "engine." Only when institutions have more than one class disciplines and complementary advantages, coordinated development of the relationship formed between disciplines in order to form a first-class discipline community. Class discipline is a manifestation of the core competitiveness of Community institutions, it brought together a world-class team of teachers, world-class research platform, leading student groups. Subject to the advantage of the engineering of Harbin Institute of Technology, for example, in recent years to develop its jurisprudence. In accordance with its institutions, a relevant person in charge said: "To really improve the ability to innovate, there must be a strong jurisprudence to support, so the school through this consideration, must be a good development of Science." 


\subsection{The Evaluation Standards of World-class Discipline}

World-class disciplines construction target is closely linked criteria class disciplines. There are indicators to evaluate what level of discipline? At home and abroad have rich practice. Our main recognized evaluation to assess the Academic Degrees and Graduate Education Development Center implemented as a reference, including teachers and resources, the level of scientific research, quality of personnel training and discipline reputation. The current evaluation and abroad "heat" higher ESI rankings are subject in different disciplines consider the agencies published in the SCI and SSCI journals and the number of scientific papers metrology performance indicators (citation frequency and cites frequency). "US News And World Report" evaluation indicators include quality assessment (peer review and evaluation of employers), the quality of students, research grants (total funding all funds and division), student-teacher ratio. British "The Times (Higher Education Supplement)" academic evaluation indicators, including peer review, student-teacher ratio, citations from the case of ESI and the degree of internationalization of the university. Discipline Evaluation Chinese Science Evaluation Research Center in Wuhan University, including SCI, SSCI and A \& HCI number of papers published, the number of hot papers (Hot Paper), is the high number of papers cited papers and citations.

Overall, the judgment discipline level indicator has three main aspects: (1) to achieve internationally comparable indicators: the number of papers SCI and SSCI journals highly cited and citation frequency, SCI and SSCI journals highly cited authors, the number of patents, international awards (Fields Medal and the Nobel prize) as well as teachers who will serve in important international organizations of teachers; (2) difficult to achieve international comparisons, but widely used in the domestic indicators: quality of students (school grades), the quality of teachers at all levels from department funds, social science fund key projects, etc.), the number of research funding, Speciality (master, doctoral, and other key disciplines (teachers have all kinds of titles, such as academicians, scholars Qianren, academics and people plan Yangtze River scholars), the degree of internationalization (the proportion of foreign students), domestic journals published papers, cited the award-winning (all levels of government incentives, incentives Society) and reproduced and various; (3) academic reputation index: peer rating score.

Of course, the Evaluation standards should be based on local subjects, in line with China's national conditions. "double world-class" construction program clear: world-class teachers should have the "ideal and faith," world-class personnel training should have the "historical mission and social responsibility," world-class scientific research should include the "Chinese characteristics, Chinese style, Chinese style "class University and the University of spiritual culture should become the basic socialist core values follow; world-class achievements should enhance the driving force of innovation resources for economic and social development of the College.

\section{Target of "Double world-class" Construction to Achieve}

"Double world-class" building programs clearly puts forward the way to achieve the objectives rely on: one by the construction; and on the reforms. Construction to Improve "hard power" of reform to enhance the "soft power." Both complement each other, can be neglected. Even some ways is concerned, there is no reform, no construction.

\subsection{Construction}

(1) Build world-class team of teachers

World-class team of teachers is the "ideal faith and moral character, have a solid educated, caring heart." This will require to achieve "introduction" and "culture" a combination of both to gather leading scientists worldwide, discipline leader and innovative team, but also by optimizing the growth and development of young teachers stand out institutional environment train young teachers and innovative team.

(2) Train Talent with Ingenuity

Characterized by top-notch innovative talents is "historical mission and social responsibility, innovative spirit and practical ability." This requires personnel training, we must be "adult" education 
guide "timber" of education, focusing on students' thinking in lead to carry out intellectual work, basic sentiment on mold and physical exercise.

(3) Enhance the level of scientific research

The key is to adhere to enhance the scientific level of some things, to strengthen top-level design and layout of the discipline of strategic planning, focusing on building a number of leading domestic and international world-class advantages disciplines and fields.

(4)Outstanding cultural heritage of innovation.

The key outstanding cultural heritage of innovation is "Strengthening the construction of university culture", "the socialist core values into the whole process of education." This requires the education process to fully play the role of cultural education "to guide the young students Diligence, virtue, discernment, probity, socialist core values become substantially follow, form an excellent school spirit, teaching style, study style."

(5) Accelerate innovation-driven source.

The key is to accelerate scientific and technological transformation "sound market-oriented, social capital participation, the results of multi-factor application transformation mechanism of deep integration" and "strengthen the science and technology and the economy, innovation projects and real productivity, innovation and industrial connection." If major scientific innovation, breakthroughs in key technologies into advanced productive forces" will be the development of a country have a significant and far-reaching impact.

\subsection{Reform}

What exactly is the reform? Generally, it is to enhance the "soft power" of institutional mechanisms to optimize construction "invisible" first-class university. Specifically, the "dual class" Construction of the reform program has five: strengthening and improving Party leadership over the universities, aims to "improve the unified leadership of party committees, party and government division of labor, coordinated operation of the working mechanism"; improve the internal governance structure, scholars scholarship intended to form, the teachers and students involved in school governance and other power distribution mode; the key to achieve a breakthrough, intended to explore effective performance-oriented personnel system and scientific operation of the system; to build social participation, aimed at strengthening discipline initiative to adapt to society capacity development, and to mobilize society in development institutions, actively support the development of institutions; to promote international exchanges and cooperation, aimed at teaching, research and realize the whole process of international high-level research institutes or universities, "collaborative innovation", thus expanding our Influence.

For the purposes of tackling the task of reforming the extent of the need for reform of the personnel system overall planning. From the point of view of reform laws, "Incremental" reform easier, because it does not "move Who cheese", but is more difficult to "stock" of the reform, as it will take a cut of stakeholders "share". Especially when stakeholders are important in the development of education subject, reform may encounter greater resistance. In the key reform, the first is the most important body composed of university - teachers. Performance-oriented reforms will break the old professor, "carefree", "eat mess" work state, to bring them to the performance of "magic", if incapable of performance appraisal, the professors may be a pay cut, or even be eliminated. When a reform crisis professors "rice bowl", it will encounter the greatest resistance. But just can not give up because of a long night waiting for the dawn, we can not because reform is not easy to give up pursuit of the future. Only true in the traditional bastion of the university to promote teachers' performance standard "hiring" and "diversion" to make "those who can afford to enter," "out of the idle energy", thus the "flow" to protect the university has first-class teachers, thereby output first-class achievements, and build first-class discipline, cultivate first-class talent.

\section{References}

[1] Guo Xinli. See cumulative distribution focus of Higher Education [J] from the university functions. Chinese higher education, 2003 (19): 17-19. 
[2] 211 inter-ministerial coordination group office. 211 Project Development Report (1995-2005) (fine) [M] Beijing: Higher Education Press, 2007: 15.

[3] Liu Tao. "985,211 dispute" should go beyond the status of the dispute [EB / OL] (2014-11-26) .http: // Education news.cn/2014-11/26/c_127251783_2.html.

[4] Zhu Xiulin. "Double world-class" Construction of 985,211 broke the barriers of identity [EB / OL] (2014-11-05) .http: //edu.people.com Cn / n / 2015/1105 / c1006-27780695.html 